\title{
ESTUDO DE ALTOS NÍVEIS DE COBRE ORGÂNICO E INORGÂNICO COMO PROMOTORES DO CRESCIMENTO DE LEITÕES
}

\author{
ISABEL ALFONSO VIEIRA LIMA \\ Zootecnista
}

Orientador: Prof. Dr. VALDOMIRO SHIGUERU MIYADA

Dissertação apresentada à Escola Superior de Agricultura "Luiz de Queiroz", da Universidade de São Paulo, para obtenção do titulo de Mestre em Agronomia, Área de Concentração: Ciência Animal e Pastagens.

\author{
P I R A C I C A B A \\ Estado de São Paulo - Brasil \\ Julho -1999
}


Dados Internacionais de Catalogação na Publicação (CIP)

DIVISÃo DE BIBLIOTECA E DOCUMENTAÇÃO - Campus “Luiz de Queiroz"/USP

\section{Lima, Isabel Alfonso Vieira}

Estudo de altos niveis de cobre orgânico e inorgânico como promotores do crescimento de leitōes / Isabel Alfonso Vieira Lima. - - Piracicaba, 1999.

$51 \mathrm{p}$.

Dissertação (mestrado) - - Escola Superior de Agricultura Luiz de Queiroz, 1999. Bibliografia.

1. Citrato cúprico 2. Crescimento animal 3. Composto orgânico de cobre 4. Desempenho animal 5. Dieta animal 6. Leitão 7. Nutriçāo animal 8. Raçāo para suíno 9. Sulfato de cobre I. Título

CDD 636.4085 
AOS MEUS DOIS AMORES, CLAUDIO E ARTHUR

À MEMÓRIA DE MEUS PAIS, JOÃO PEDRO E GRACINDA, 


\section{AGRADECIMENTOS :}

À CAPES, pela concessão da Bolsa durante o curso;

Ao Prof. Dr. Valdomiro Shigueru Miyada, pela confiança e orientação;

Ao Prof. Dr. José Fernando Machado Menten, pelo auxílio e sugestões;

Aos funcionários do Setor de Suinocultura do Departamento de Produção Animal da ESALQ (Srs. Pires e Ventura);

Aos estagiários do Setor de Suinocultura do Departamento de Produção Animal da ESALQ, Márcia e Eros, pelo auxílio na implantação e no transcorrer da fase de campo do experimento;

Aos colegas de turma José Aparecido, Marcos e Alcester, pelo auxílio na confeç̧ão das rações do experimento;

Ao Zootecnista Paulo de Tarso Cardoso Nobre, pelo auxílio e sugestões.

À empresa M CASSAB, pelo fornecimento da lactose, soro de leite e plasma, utilizados nestes experimento;

À empresa SUPRE MAIS, em nome do Prof. Dr. José Eduardo Butolo pelo auxílio e colaboração, bem como pelo fornecimento do premix vitamínico e mineral; 


\begin{abstract}
$\grave{A}$ empresa Goldschmidt Chemical Specialities, pelo fornecimento do citrato cúprico.
\end{abstract}

Ao Sr Wanderlei Bresciani e aos funcionários do Sítio Santo André, pela ajuda no fornecimento dos animais;

Aos amigos da empresa SUPRE MAIS, que de uma forma ou outra, contribuíram para a realização deste;

A todos aqueles, que, de alguma forma, contribuíram para a realização deste trabalho e que não estão aqui citados, o meu agradecimento. 


\section{SUMÁRIO}

Página

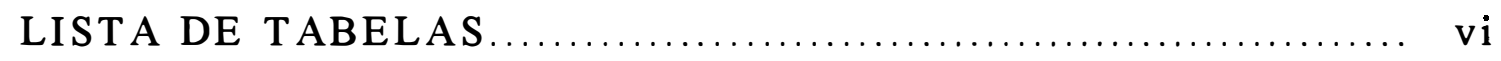

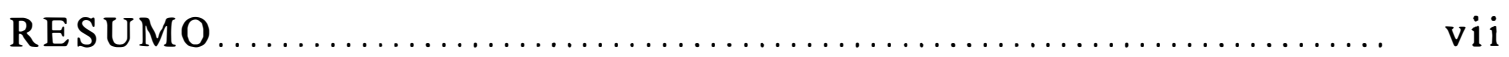

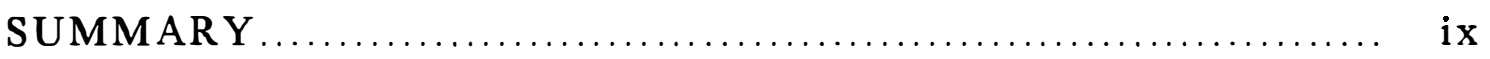

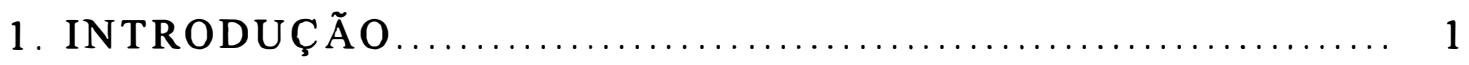

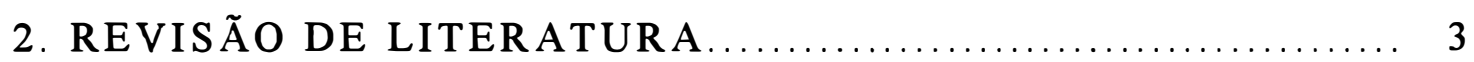

2.1. Cobre e rações complexas na produção de suínos ........ 3

2.2. Solubilidade das fontes de cobre....................... 6

2.3. Modo de ação do cobre................................ 9

2.3.1. Efeito na economia de nutrientes................ 10

2.3.2. Efeito de proteção - redução na produção de amônia............................................. 11

2.3.3. Efeito metabólico.............................. 12

2.4. Interação cobre x zinco ................................. 15

2.5. Altos níveis de zinco para controle de diarréia pósdesmame de leitões..................................... 16

3. MATERIAL E MÉTODOS ................................... 19

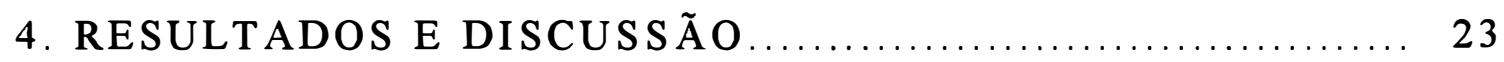

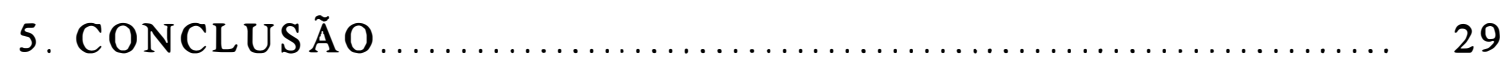

REFERÊNCIAS BIBLIOGRÁFICAS ...................... 30

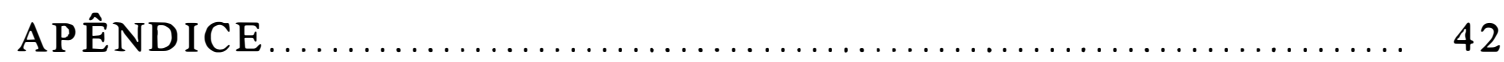


TABELA N ${ }^{\circ}$.

Página

1 Composição percentual e valores calculados das dietas basais...............................

2 Médias das características de performance dos leitões em recria alimentados com ração contendo sulfato de cobre e níveis crescentes de citrato cúprico - 1 a 14 dias............................................

3 Médias das características de performance dos leitões em recria alimentados com ração contendo sulfato de cobre e níveis crescentes de citrato cúprico -15 a 28 dias.

4 Médias das características de performance dos leitões em recria alimentados com ração contendo sulfato de cobre e níveis crescentes de citrato cúprico - 1 a 28 dias 


\title{
ESTUDO DE ALTOS NÍVEIS DE COBRE ORGÂNICO E INORGÂNICO COMO PROMOTORES DO CRESCIMENTO DE LEITÕES
}

\author{
Autora : ISABEL ALFONSO VIEIRA LIMA \\ Orientador: Prof. Dr. VALDOMIRO SHIGUERU MIYADA
}

\section{RESUMO}

O presente estudo teve por objetivo avaliar a eficácia do cobre orgânico (citrato cúprico) comparado ao inorgânico (sulfato de cobre penta-hidratado), como agente promotor do crescimento de leitões alimentados com uma ração complexa.

Foram utilizados 80 leitões (40 machos castrados e 40 fêmeas) obtidos do cruzamento de fêmeas Agroceres Fl com machos terminadores Agroceres 405, desmamados aos $21 \pm$ dias de idade com peso médio inicial de $6,85 \mathrm{~kg}$. Os tratamentos consistiram de uma ração basal constituída de milho, farelo de soja, lactose, leite em pó desnatado e plasma sangüíneo (controle), ou essa ração basal com $200 \mathrm{ppm}$ de $\mathrm{Cu}$ proveniente de sulfato de cobre penta-hidratado, ou 50,100 e $150 \mathrm{ppm}$ de $\mathrm{Cu}$ provenientes do citrato cúprico. Nos primeiros 14 dias experimentais, todas as rações continham $2500 \mathrm{ppm}$ de $\mathrm{Zn}$ na forma de óxido de zinco. Água e ração farelada foram fornecidas à vontade durante todo o período experimental de 28 dias. Os animais foram alojados em 20 
gaiolas metálicas suspensas com dimensão de $1,50 \times 1,20 \mathrm{~m}$, sendo que cada uma continha bebedouro e comedouro automáticos. O delineamento experimental foi o de blocos casualizados com quatro repetições por tratamento e quatro leitões ( 2 machos castrados e 2 fêmeas) por unidade experimental (baia). As pesagens dos animais e o cálculo do consumo de ração, ganho diário de peso e conversão alimentar foram feitas semanalmente. Não foram observadas diferenças significativas $(P>0,05)$ entre os tratamentos para o ganho diário médio de peso, consumo diário médio de ração e para a conversão alimentar média dos leitões nos diversos periodos considerados. Mesmo após o desdobramento dos graus de liberdade do fator nível de $\mathrm{Cu}$ orgânico em seus componentes individuais, não foi detectado qualquer efeito do $\mathrm{Cu}$ sobre a performance dos leitões.

Assim, não ficou evidenciada a atividade promotora do crescimento dos altos níveis de $\mathrm{Cu}$ orgânico (citrato cúprico) ou inorgânico (sulfato de cobre penta-hidratado) em leitões recémdesmamados alimentados com ração complexa. 


\title{
HIGH DIETARY LEVELS OF ORGANIC AND INORGANIC COPPER AS GROWTH PROMOTERS OF WEANLING PIGS
}

\author{
Author: ISABEL ALFONSO VIEIRA LIMA
}

Adviser: Prof. Dr. VALDOMIRO SHIGUERU MIYADA

\section{SUMMARY}

An experiment was conducted to evaluate high dietary levels of organic and inorganic $\mathrm{Cu}$, respectively, cupric citrate and copper sulfate, as growth promoters of weanling pigs fed complex diet. Eighty crossbred weanling pigs ( 40 castrated males and 40 females), averaging $6,85 \mathrm{~kg}$ initial weight and $21 \pm 2$ days of age, were assigned to 5 treatments in a randomized complete block design based on genetic group, sex and live weight. The treatments consisted in a basal diet of corn soybean meal, lactose, dried skim milk and spray dried porcine plasma meal (control), or the basal diet containing $200 \mathrm{ppm}$ of inorganic $\mathrm{Cu}$ (as $\mathrm{Cu} \mathrm{SO} \mathrm{SO}_{4} 5 \mathrm{H}_{2} \mathrm{O}$ ), or 50 , 100 and $150 \mathrm{ppm}$ of organic $\mathrm{Cu}$ (as $\mathrm{C}_{6} \mathrm{H}_{4} \mathrm{Cu}_{2} \mathrm{O}_{7}$ ). The basal diet was supplemented with $2500 \mathrm{ppm}$ of $\mathrm{Zn}$ (as $\mathrm{ZnO}$ ) during the first 14 days of experimental period. Pigs were housed in 20 pens with 4 pigs ( 2 castrated males and 2 females) per pen (experimental unit) and 4 replications per treatment. Feed and water were given ad libitum to pigs during all 28-day experimental period. Pigs were weighed individually and the data of feed intake/pen were 
registered every week. Average daily gain, daily feed intake and feed conversion were not affected $(P>0,05)$ by high dietary levels of copper. Therefore, high dietary levels of organic, as cupric citrate, and inorganic, as copper sulfate, did not show any growth promoter effect on weanling pigs fed complex diet. 


\section{INTRODUÇÃ O}

O cobre $(\mathrm{Cu})$ é classificado nutricionalmente como um micromineral essencial. Por mais de 40 anos ele vem sendo estudado e adicionado às rações de suínos, como promotor do crescimento, principalmente na fase pós-desmame, em doses muito superiores àquelas exigidas pelos leitões. Inúmeros trabalhos têm demonstrado melhora na conversão alimentar, aumento no ganho de peso e redução da mortalidade quando elevados níveis deste micromineral são incorporados às dietas dos leitões.

Estudos também demonstram que a eficácia na ação promotora do crescimento deste micromineral é dependente da solubilidade do sal de cobre em água, bem como da disponibilidade biológica da fonte.

- A adição do sulfato de $\mathrm{Cu}$ penta-hidratado $\left(\mathrm{CuSO}_{4} .5 \mathrm{H}_{2} \mathrm{O}\right)$ na concentração de 125 a $250 \mathrm{ppm}$ de $\mathrm{Cu}$ na ração tornou-se uma recomendação clássica de uso, devido à sua comprovada atividade promotora do crescimento de suínos. Pesquisas recentes estão sendo feitas com a finalidade de avaliar novas fontes de $\mathrm{Cu}$, principalmente aquelas de forma orgânica, aparentemente mais biodisponíveis do que as formas inorgânicas. O citrato cúprico $\left(\mathrm{C}_{6} \mathrm{H}_{4} \mathrm{Cu}_{2} \mathrm{O}_{7}\right)$ vem ser uma destas fontes, cujo estudo prévio com frangos de corte mostrou-se tão ou mais eficiente do 
que o sulfato de $\mathrm{Cu}$ penta-hidratado $\left(\mathrm{CuSO}_{4} \cdot 5 \mathrm{H}_{2} \mathrm{O}\right)$.

- O uso de rações complexas com inclusão de 2500 a 3000 ppm de $Z$ n, nos primeiros 14 dias após o desmame de leitões aos 21 dias de idade, tornou-se prática usual na maioria das granjas brasileiras que adota o sistema de criação intensivo. Avaliações econômicas e técnicas indicam que os gastos superiores do uso de uma ração complexa é compensado pela redução nos quadro de diarréia fisiológica, menor taxa de mortalidade nos primeiros dias pós-desmame, bem como, um melhor desempenho obtido durante todo o período subsequente de criação.

O principal objetivo desta pesquisa foi avaliar a eficácia de altos níveis de $\mathrm{Cu}$, na forma de citrato cúprico, como agente promotor do crescimento de leitões em comparação ao sulfato de cobre penta-hidratado. 


\section{REVISÃO DE LITERATURA}

\subsection{Cobre rações complexas na produção de suínos}

$\mathrm{O} \mathrm{Cu}$ é classificado como um micromineral essencial e a sua exigência para suínos jovens está em torno de 6 ppm na ração (NRC, 1998).

Nos últimos 40 anos, inúmeras pesquisas comprovaram que elevados níveis dietéticos de $\mathrm{Cu}$ apresentam uma atividade promotora do crescimento. As pesquisas tornaram-se mais consistentes a partir de meados da década de 50 e início de 60, sendo que neste período Barber et al. (1955), Bunch et al. (1961) e Hawbaker et al. (1961) já constataram a eficiência do sulfato de $\mathrm{Cu}$ penta-hidratado $\left(\mathrm{CuSO}_{4} .5 \mathrm{H}_{2} \mathrm{O}\right)$ como agente promotor do crescimento de suínos, quando utilizado em concentrações de 125 a 250 ppm de $\mathrm{Cu}$ na ração.

Os resultados de desempenho de suínos, obtidos nos trabalhos com elevados níveis de $\mathrm{Cu}$ na ração, apresentam uma certa semelhança. Compilando 12 experimentos realizados na Universidade de Kentucky entre 1978 e 1983, Cromwell (1991) verificou uma melhora média de $24 \%$ no ganho de peso e $9,7 \%$ na conversão alimentar. Os resultados das pesquisas no Brasil não se 
distanciam daqueles obtidos no exterior. Possobon (1991) observou $24,5 \%$ de melhora no ganho diário de peso e $3,1 \%$ na conversão alimentar e Menten (1995) obteve melhora de $34 \%$ e $8,7 \%$ para os mesmos parâmetros, com uma dieta à base de milho e farelo de soja.

O conceito de uso de dietas complexas para leitões data da década de 60. Bayley \& Carlson (1970); Lepine et al. (1991); Meade et al. (1969); Okai et al. (1976) e Zimmerman \& Khajarern (1973) foram unânimes em afirmar que as dietas complexas estimulam um maior consumo de ração pelos leitões e, consequentemente, se obtém melhor desempenho.

Ball \& Aherne (1987) observaram uma interação significativa entre idade do desmame e dieta, sendo que dietas complexas estimularam o ganho de peso de leitões desmamados aos 21 dias de idade. As mesmas respostas não foram obtidas para aqueles desmamados aos 28 dias de idade. Estes dados foram confirmados por Berto et al. (1997).

A maioria dos trabalhos citados nesta revisão, que avaliaram o $\mathrm{Cu}$ como promotor do crescimento de leitões, utilizou dietas dos leitões baseadas em milho e farelo de soja. Menten (1995) salientou que o uso de uma dieta simples é mais adequada por permitir a expressão do agente promotor do crescimento. Mais recentemente, pesquisadores passaram a analisar o comportamento deste mineral em dietas com ingredientes de maior digestibilidade e melhor palatabilidade. Edmonds et al. (1985) verificaram que a adição de $250 \mathrm{ppm} \mathrm{de} \mathrm{Cu}$ na forma de $\mathrm{CuSO}_{4} \cdot 5 \mathrm{H}_{2} \mathrm{O}$, em rações à base de milho e soja proporcionou uma consistente melhora no ganho de peso de leitões, particularmente, na primeira semana pós-desmame. Porém, quando adicionou $25 \%$ de soro de leite em pó à dieta, não se observou uma resposta significativa à adição do 
cobre como agente promotor do crescimento. Smith et al. (1997), também, não observaram diferenças no ganho diário de peso e consumo de ração de leitões desmamados aos 13 dias de idade que receberam dieta complexa enriquecida com 250 ppm de $\mathrm{Cu}$.

- O interesse pelo uso do $\mathrm{Cu}$ é devido ao seu baixo custo comparado ao dos antibióticos. Além disso, atualmente vários países, tanto das Américas como os da União Européia, estão sofrendo restrições quanto ao uso de aditivos antimicrobianos, devido a possibilidade do desenvolvimento de resistência bacteriana a determinados antibióticos e quimioterápicos, existindo ao mesmo tempo uma resistencia cruzada em relação a outros antibióticos empregados nos seres humanos (Muirhead, 1998).

Recentemente, uma nova questão vem sendo levantada junto ao meio científico e diz respeito à poluição ambiental decorrente do excesso de cobre presente nas fezes, bem como na água de escalda no abate de animais que recebem altas doses deste mineral. Para tanto, as pesquisas estão sendo feitas com o intuito de se obterem fontes mais biodisponíveis, que possam promover sistematicamente uma melhora no desempenho e reduzir a deposição do $\mathrm{Cu}$ no solo e água. Pesti \& Bakalli (1996) avaliaram o citrato cúprico em dietas para aves de corte, comparado ao sulfato de $\mathrm{Cu}$ penta-hidratado e concluíram que o citrato cúprico pode ser utilizado em níveis inferiores ao sulfato, com a mesma eficiência como promotor do crescimento e com uma redução na quantidade de cobre na cama. Os resultados de desempenho obtidos neste experimento foram posteriormente confirmados por Konjufca et al. (1997) e Ewing et al. (1998). 


\subsection{Solubilidade das fontes de cobre}

O interesse pela avaliação das fontes de cobre surgiu paralelamente às pesquisas que estudaram este mineral como agente promotor do crescimento.

Underwood (1977) afirmou que, nos monogástricos, o $\mathrm{Cu}$ é absorvido principalmente na parte anterior do intestino delgado, região de pH ácido. A sua magnitude de absorção é dependente da espécie e "status" animal, da presença de outros compostos na dieta (fitatos, $\mathrm{Ca}, \mathrm{Zn}, \mathrm{Fe}, \mathrm{Pb}$ e $\mathrm{S}$ ) e da forma química que o cobre é consumido. No geral, a absorção é baixa, sendo que 5 a $10 \%$ do $\mathrm{Cu}$ consumido é absorvido e retido. Assim, em condições normais, cerca de $90 \%$ ou mais do $\mathrm{Cu}$ ingerido aparece nas fezes. A maioria do $\mathrm{Cu}$ fecal é $\mathrm{Cu}$ dietético não absorvido. Porém, parte é proveniente da bile que é a principal via de excreção cúprica. Mc Dowell (1992) complementou afirmando que a homeostase é afetada pela taxa de absorção do $\mathrm{Cu}$ que, por sua vez, é regulada pela mucosa intestinal. Existe uma forte evidência de que a absorção do $\mathrm{Cu}$ é regulada pela necessidade do organismo e que a metalotioneina nas células epiteliais do intestino é a responsável por esta regulação. O mecanismo de absorção do $\mathrm{Cu}$ parece ser dependente do grau de saturação do meio. Quando o meio está saturado observa-se o transporte ativo e em meio insaturado têmse a difusão passiva.

Para avaliação das potenciais fontes de $\mathrm{Cu}$ destinadas à nutrição animal, os pesquisadores dispõem da técnica da biodisponibilidade, onde se quantifica o teor do mineral presente no fígado de animais previamente alimentados com uma ração contendo níveis elevados do $\mathrm{Cu}$. Ledoux et al. (1991) afirmaram 
que a grande vantagem deste método deve-se ao fato de as diferenças entre as fontes poderem ser detectadas com poucas observações.

-Cromwell et al. (1989) sugeriram que a solubilidade em água de uma fonte de cobre é a medida para sua eficiência como promotor do crescimento e uma fonte solúvel apresenta boa biodisponibilidade, concluindo que biodisponibilidade e efeito promotor do crescimento estão correlacionados.

Os sulfatos, carbonatos, cloretos, óxidos e inúmeros complexos orgânicos de $\mathrm{Cu}$ têm sido reportados como efetivos promotores do crescimento. Porém, observa-se variação no desempenho dos animais de acordo com a forma oferecida. Bunch et al. (1961) foram um dos primeiros a comparar o sulfato de $\mathrm{Cu}$ $\left(\mathrm{CuSO}_{4} .5 \mathrm{H}_{2} \mathrm{O}\right)$ ao óxido cúprico $(\mathrm{CuO})$, onde constataram que as duas fontes melhoraram significativamente o ganho de peso de leitões. Esta pesquisa foi contestada por Cromwell et al. (1989), onde os autores observaram que o desempenho e a concentração do $\mathrm{Cu}$ no fígado de leitões suplementados com $\mathrm{CuO}$ foi muito inferior à obtida no lote suplementado com $\mathrm{CuSO}_{4} .5 \mathrm{H}_{2} \mathrm{O}$, demonstrando que o $\mathrm{CuO}$ é ineficiente como promotor do crescimento.

A comparação da biodisponibilidade de diversas fontes de Cu fez com que Baker et al. (1991) verificassem uma eficácia de $115,15 \%$ para um complexo Cu-lisina, 92,5\% para o $\mathrm{CuO}_{2}$ e de $-1,7 \%$ para o $\mathrm{CuO}$, considerando como padrão $100 \%$ do $\mathrm{CuSO}_{4} .5 \mathrm{H}_{2} \mathrm{O}$.

: A avaliação do cloreto de cobre tribásico, feita por Miles et al. (1998), permitiu que os autores concluíssem que a biodisponibilidade desta fonte varia entre 90 até $106 \%$ em relação 
ao sulfato de cobre penta-hidratado.

A superioridade das fontes orgânicas em relação às fontes inorgânicas do $\mathrm{Cu}$ foi confirmada por Zhou et al. (1994a) que verificaram melhora no ganho de peso de leitões quando utilizaram rações suplementadas com $\mathrm{Cu}$-lisina em relação àqueles que receberam sulfato de $\mathrm{Cu}$ penta-hidratado.

Os resultados, obtidos por Pesti \& Bakalli (1996) com o uso do citrato cúprico para frangos de corte, estimularam o interesse por novos estudos, para avaliação do comportamento deste produto tanto para aves como para suínos. Ewing et al. (1998) também confirmaram a eficiência do citrato cúprico, oxicloreto de $\mathrm{Cu}$ e do sulfato de $\mathrm{Cu}$ penta-hidratado como agentes promotores do crescimento para frangos de corte, sendo que as melhores respostas de ganho de peso e conversão alimentar se deram com o uso do citrato cúprico.

$\mathrm{O}$ citrato cúprico $\left(\mathrm{C}_{6} \mathrm{H}_{4} \mathrm{Cu}_{2} \mathrm{O}_{7}\right)$, cuja nomenclatura química vem a ser 2-hidroxi-1,2,3-propanotricarboxílico sal ácido de cobre, é uma fonte orgânica de $\mathrm{Cu}$, preparado via interação quente de soluções de sulfato de cobre e citrato de sódio. Apresenta peso molecular de 315,18 e $22,86 \%$ de $\mathrm{C}, 1,28 \% \mathrm{H}$, $40,32 \% \mathrm{Cu}$ e $35,53 \%$ de $\mathrm{O}$. Sua cor é verde, quando hemipentahidratado, forma de cristal e é inodoro (The Merck Index, 1983). O citrato cúprico também pode apresentar-se na forma monohidratado, sendo que a concentração aproximada é de 36,5 a $37,7 \% \mathrm{Cu}$ e peso molecular 342, de coloração azulada e é menos higroscópico que a forma hemipentahidratado (Goldschmidt Chemical Specialities ${ }^{1}$ )

\footnotetext{
${ }^{1}$ TH. GOLDSCHMIDT INDUSTRIECHEMIKALIEN GmbH Mülheimer Str. 16-22, D- 68219 Mannheim/Germany
} 


\subsection{Modo de ação do cobre}

Todas as pesquisas feitas até então com o $\mathrm{Cu}$ têm como finalidade, direta ou indireta, elucidar o seu modo de ação como agente promotor do crescimento. Elliot \& Amer (1973) afirmaram que a ação promotora do crescimento do cobre foi inicialmente atribuída à atividade antimicrobiana, similar a dos antibióticos. Porém, nem o sítio exato, nem o mecanismo de ação foram esclarecidos. Menten (1995) complementou que desde o início do uso de agentes antimicrobianos como promotores do crescimento de animais, se reconheceu que a resposta obtida era decorrente de sua ação sobre a microflora intestinal e que uma das linhas mais convincentes é o fato de aves e suínos isentos de qualquer contaminação ("germe-free") não têm seu crescimento melhorado, quando recebem ração suplementada com estes aditivos. Shurson et al. (1990) observaram alterações nas características intestinais e uma ligeira intoxicação de leitões "germe-free" alimentados com ração suplementada com $250 \mathrm{ppm}$ de $\mathrm{Cu}$. Os autores sugeriram que leitões na condição "germe-free" podem absorver mais eficientemente ou apresentam uma baixa exigência ou habilidade de utilização do excesso do $\mathrm{Cu}$. Etheridge et al. (1984 a,b) verificaram que o tipo de dieta altera a microflora intestinal de leitões recém-desmamados, sendo que rações à base de milho e soja induzem um aumento do número de bactérias e coliformes. Já Bunch et al. (1961) obtiveram uma alteração na microflora intestinal com o uso de sulfato de $\mathrm{Cu}$ na ração de leitões, sendo que as mais consistentes mudanças deram-se na concentração de microrganismos aeróbicos e anaeróbicos. Comparando agentes antimicrobianos em doses subterapêticas, 
Radecki et al. (1990) não observaram efeito do $\mathrm{Cu}$, carbadox ou tetraciclina sobre o número de bactérias totais no conteúdo do jejuno ou do colo de leitões. Em sua revisão, Visek (1978) afirmou que há uma forte evidência de que os agentes antimicrobianos podem induzir uma alteração na proporção da população bacteriana ou mesmo de mudança no metabolismo das bactérias e não redução delas.

O Cu participa da respiração celular, formação óssea, funções cardíacas, desenvolvimento do tecido conectivo, mielinização das células nevosas, queratinização e pigmentação dos tecidos. É também um componente essencial de inúmeras importantes metaloenzimas, incluindo as citocromo oxidases, lisil oxidase, superóxido desmutase e tirosinase (Mc Dowell, 1992). Estas importantes funções no metabolismo animal, bem como as respostas obtidas nos diversos trabalhos levaram muitos autores a concluírem que o $\mathrm{Cu}$ como agente promotor do crescimento poderia estar atuando de forma mais ampla do que ser apenas um agente antimicrobiano.

Wallace (1970) afirmou que seriam três os principais modos de ação dos agentes promotores do crescimento: economia de nutrientes, efeito metabólico e controle de doenças subclínicas. Os fatores estudados e que são determinantes para entender o modo de ação do $\mathrm{Cu}$ serão citados a seguir.

\subsubsection{Efeito na economia de nutrientes}

Medir a taxa de retenção do nitrogênio (N) e a digestibilidade dos nutrientes são duas opções para avaliação da 
eficiencia de um agente promotor do crescimento. Comparando o uso de $55 \mathrm{ppm}$ de carbadox e níveis crescentes de $\mathrm{Cu}$, Roof \& Mahan (1982) concluiram que o carbadox estimula a retenção de $\mathrm{N}$ em leitões, sendo que o mesmo resultado não foi obtido com o $\mathrm{Cu}$, já que nem a dose de $250 \mathrm{ppm}$ de $\mathrm{Cu}$ foi efetiva no estímulo ao ganho de peso. Por outro lado, Dove (1995) verificou que 250 ppm de $\mathrm{Cu}$ promoveram uma melhora significativa na retenção de $\mathrm{N}$, digestibilidade aparente da matéria seca, tanto em dietas com baixo teor de gordura como aquela enriquecida com $5 \%$ de gordura animal.

Outra metodologia aplicada vem a ser aquela que mede as alterações na taxa de oxigênio gasto pelo trato digestivo, pâncreas e baço do animal teste. Yen \& Nienaber (1993) observaram que $250 \mathrm{ppm}$ de $\mathrm{Cu}$ não foi eficaz na redução da demanda energética do trato digestivo de marrãs, concluindo que são outros os efeito promotores de crescimento que exerce este mineral em suínos.

\subsubsection{Efeito de proteção - redução na produção de amônia}

A amônia $\left(\mathrm{NH}_{3}\right)$ é uma substância tóxica produzida geralmente pela flora intestinal dos animais. A sintese da amônia dá-se pela ação da urease (uma enzima sintetizada por microrganismo ou plantas) sobre a uréia que por sua vez é obtida pela deaminação de aminoácidos ou pela ação de outros compostos nitrogenados. Verificou-se que animais, recebendo altas doses ou mesmo níveis subterapêuticos de antibióticos, tiveram a concentração de amônia do intestino e da veia porta reduzida 
(Visek, 1978). A suplementação de dietas de leitões com 250 ppm de $\mathrm{Cu}$ permitiu Menten et al. (1988) verificarem uma tendência de redução do conteúdo de amônia no jejuno e colo transverso. Por outro lado, no sangue portal observou-se uma menor concentração da amônia, resultado semelhante àquele obtido por Yen \& Nienaber (1993). Tais resultados refletem o decréscimo da hidrólise da uréia e, consequentemente, redução na produção de amônia pelos microrganismos intestinais. Menten (1995) observou uma redução de cerca de $20 \%$ na concentração de amônia na veia porta. Para a concentração de amônia no conteúdo intestinal não foram obtidos resultados similares aos citados anteriormente, sendo que o autor recomenda cautela na interpretação destes dados face a possíveis problemas ligados à coleta das amostras.

\subsubsection{Efeito metabólico}

O comprovado efeito promotor do crescimento e as funções bioquímicas, que o $\mathrm{Cu}$ exerce no organismo animal, fez com que Dove (1992) levantasse a possibilidade de que os níveis elevados do $\mathrm{Cu}$ poderiam melhorar a eficiência de algum sistema enzimático. O efeito sobre o metabolismo de aves e suínos exercido pelas altas doses do $\mathrm{Cu}$ está sendo estudado e os resultados obtidos torna consistente a afirmação acima. O fígado e o cérebro são os órgãos que apresentam uma significativa incorporação do excesso de $\mathrm{Cu}$ dietético em relação aos demais órgãos e sistemas (Ledoux et al., 1991). Tem-se observado que a enzima superóxido dismutase, uma cuproenzima que tem a finalidade de eliminar os radicais livres do organismo animal, 
responde positivamente à suplementação de $250 \mathrm{ppm}$ de $\mathrm{Cu}$ na dieta Zhou et al. (1994 b). Assim, o excesso de $\mathrm{Cu}$ na dieta, além de ser depositado no fígado e cérebro, também, promove um aumento desta metaloenzima. Zhou et al. (1994a, b) observaram, também, que altos níveis de $\mathrm{Cu}$ na dieta estimularam a produção do hormônio do crescimento pela pituitária, gerando a hipótese de que o $\mathrm{Cu}$ pode estimular a síntese de GHmRNA e de "possíveis fatores de crescimento" que atuarão em conjunto para a melhoria no desenvolvimento dos suínos.

- Dietas ricas em $\mathrm{Cu}$, também, alteram o metabolismo dos lipídios e promovem uma mudança no tipo do tecido adiposo dos animais. Amer \& Elliot (1973), avaliando o toucinho de suínos, observaram um decréscimo da quantidade de ácidos graxos saturados em relação aos insaturados, quando do uso de $250 \mathrm{ppm}$ de $\mathrm{Cu}$ nas fases de crescimento e terminação. O mesmo nível de $\mathrm{Cu}$ fez com que Myres \& Bowland (1973) verificassem uma redução na deposição de gordura na carcaça de suínos. Bakalli et al. (1995) observaram que $250 \mathrm{ppm} \mathrm{Cu}$ reduziu tanto a síntese de glutationa como a deposição de colesterol no plasma e gordura do peito de frangos. Os autores concluíram que esta mudança é decorrente da redução da glutationa pois é ela que regula a biossíntese do colesterol pela ativação da enzima 3-hidroxi-3-metilglutaril coenzima A redutase. Pesti \& Bakalli (1996) e Konjufca (1997) verificaram que as alterações no metabolismo dos lipídios são dependentes da fonte e níveis de $\mathrm{Cu}$ utilizados, sendo que a redução do colesterol hepático, plasmático e muscular se dá com o uso de $63 \mathrm{ppm} \mathrm{Cu}$ na forma de citrato cúprico e $180 \mathrm{ppm} \mathrm{Cu}$ na forma de sulfato de $\mathrm{Cu}$ penta-hidratado.

Leitões desmamados aos 21 e 28 dias de idade são incapazes de utilizar eficientemente dietas ricas em gordura (Cera 
et al., 1988, 1989; Howard et al., 1990 e Lawrence \& Maxwell, 1983). A significativa melhora no ganho de peso, bem como as alterações na proporção dos ácidos graxos séricos de leitões, alimentados com dietas contendo $250 \mathrm{ppm}$ de $\mathrm{Cu}$ e $5 \%$ de gordura animal, permitiram que Dove \& Haydon (1992) concluíssem que o $\mathrm{Cu}$ tem um importante papel na utilização e possivelmente no metabolismo das gorduras dietéticas e que seu efeito promotor do crescimento pode estar relacionado com as alterações na concentração dos ácidos graxos das células ou no aumento da digestibilidade ou absorção destes ácidos graxos pelo trato digestivo.

Sabe-se que o consumo de alimento é um dos fatores limitantes para o bom desenvolvimento de leitões (Okai et al., 1976) e que o uso de dietas com níveis elevados de $\mathrm{Cu}$ estimulam o consumo de ração pelos suínos (Cromwell et al., 1989; Dove \& Haydon, 1991, 1992; Dove, 1995; Roof \& Mahan, 1982; Stahly et al., 1980 e Zhou et al., 1994b).

Zhou et al. (1994a) observaram que o efeito promotor do crescimento do $\mathrm{Cu}$ é significativamente reduzido quando os leitões sofreram uma restrição alimentar, levando os autores a sugerirem que um dos principais efeitos do $\mathrm{Cu}$ vem a ser justamente no estímulo do consumo.

Doses crescentes de histidinato de $\mathrm{Cu}$ foram injetadas em leitões desmamados e verificou-se nestes animais a mesma resposta no aumento do ganho de peso, consumo de ração e variações metabólicas comparada com aquela obtida com os que recebiam Cu via dieta. Com este experimento Zhou et al. (1994b) estabeleceram a hipótese de "ação sistêmica" do cobre como agente promotor do crescimento. 


\subsection{Interação cobre xinco}

Underwood (1977) comentou que muitas discrepancias observadas, quando se utilizam altos níveis de $\mathrm{Cu}$, devem-se à concentração de $\mathrm{Zn}$ e $\mathrm{Fe}$ existente na dieta basal. Estes minerais competem entre si desde os sítios de absorção (onde ligam-se às mesmas proteínas transportadoras) até nas reações metabólicas, onde apresentam afinidade pelas mesmas enzimas. Hill et al. (1996) verificaram uma redução da enzima superóxido desmutase, quando do uso de $3000 \mathrm{ppm}$ de $\mathrm{Zn}$ e $250 \mathrm{ppm} \mathrm{de} \mathrm{Cu}$ em relação ao uso exclusivo da elevada dose do $\mathrm{Cu}$. Tem-se observado que dietas ricas em $\mathrm{Cu}$ estimulam um aumento do $\mathrm{Zn}$ no fígado (Gipp et al., 1973; Roof \& Mahan, 1982; Shurson et al., 1990; Zhou et al., 1994b). Estes resultados são conhecidos desde a década de 60 e já nesta época Ritchie et al. (1963) concluíram que leitões alimentados com excesso de $\mathrm{Cu}$, a menos que recebam uma suplementação de $\mathrm{Zn}$ ou $\mathrm{Fe}$, apresentam um quadro de intoxicação. Por outro lado, o estímulo à absorção do $\mathrm{Zn}$ provocado pelo $\mathrm{Cu}$ faz com que haja uma redução nos sintomas de paraqueratose. Já o $\mathrm{Zn}$ suplementar da dieta resulta em redução na concentração do $\mathrm{Cu}$ no fígado (Barber et al., 1960). Sendo assim, o $\mathrm{Zn}$ pode estar relacionado com a redução do efeito tóxico do $\mathrm{Cu}$, quando níveis elevados deste mineral é oferecido aos suínos (Hanrahan \& O'Grady, 1968).

Altos níveis dietéticos de $\mathrm{Zn}$ apresentam, normalmente, uma atividade promotora do crescimento. Observamse melhoras significativas no ganho de peso, consumo de ração e conversão alimentar de leitões, quando do uso de 2000 a 3000 ppm de $\mathrm{Zn}$ na dieta (Botelho, 1996; Lima et al., 1994; Menten et al., 
1992 e Miyada et al., 1993, 1994).

As dietas complexas podem afetar os resultados de desempenho de leitões suplementados com elevadas doses de $\mathrm{Zn}$. Le Mieux et al. (1996) observaram melhoras efetivas no desempenho de leitões desmamados aos $6,45 \mathrm{~kg}$ de peso vivo e alimentados com dieta complexa enriquecida com 3000 ppm de $\mathrm{Zn}$. Já Smith et al. (1997) obtiveram resultados positivos do uso do $\mathrm{Zn}$ em dietas complexas, quando os leitões foram desmamados aos 13 dias de idade, mas não quando o desmame foi aos 21 dias de idade.

$\mathrm{O}$ uso conjunto de elevadas doses de $\mathrm{Cu}$ e $\mathrm{Zn}$ vem sendo estudado há muito tempo. Ritchie (1963) verificou que as combinações de 125 ou 250 ppm de $\mathrm{Cu}$ com 100 ppm Zn às rações não são tão eficientes quanto a inclusão de apenas um destes minerais.

Hill et al. (1996) observaram uma significativa ação promotora do crescimento pela inclusão de $3000 \mathrm{ppm}$ de $\mathrm{Zn}$ com $250 \mathrm{ppm}$ de cobre. Porém, a resposta não foi aditiva, quando comparada com o uso individual dos minerais. Resultados semelhantes foram obtidos por Smith et al. (1997), com o uso de dieta complexa e desmame aos 13 dias de idade.

\subsection{Altos níveis de zinco dietético para o controle de diarréia pós-desmame de leitões}

O desmame aos 21-28 dias é uma das principais formas de estresse a que são submetidos os leitões (Etheridge et al., 1984a). A separação da mãe e do leite materno, que é sua principal fonte imunitária (Muller, 1990), a mudança para 
instalações, que muitas vezes não apresentam condições satisfatórias de temperatura e umidade (Etheridge et al., 1984a), contaminação microbiana da água, baixo peso médio e desuniformidade da leitegada ao desmame (Brito \& Mores, 1992), bem como o fornecimento de rações ricas em alimentos de origem vegetal (Etheridge et al., 1984a) a animais que apresentam uma inadequada atividade enzimática para digerir nutrientes de uma dieta à base de cereais (Zimmerman \& Khajarern, 1977), podem gerar um quadro clínico denominado de "síndrome da má absorção" (Kyriakis, 1989). As características principais desta síndrome são as mudanças degenerativas na estrutura das vilosidades intestinais e, consequentemente, alterações digestivas com o aumento de excreção de carboidratos, ácidos graxos e fezes aquosas. Bertol \& Brito (1995) afirmaram que a "síndrome da má absorção" associada a alterações do pH intestinal e o desequilíbrio no sistema imunológico favorecem a multiplicação de diversos agentes infecciosos e parasitários no intestino delgado do leitão recém-desmamado, levando à alta incidência de diarréia nesta fase. Etheridge et al. (1984b) afirmaram que a baixa digestibilidade das dietas vem ser a causa primordial para o surgimento de diarréia de leitões desmamados entre 21 e 28 dias de idade. Os resíduos não degradados dos alimentos são substratos para intensificação da fermentação pela microflora intestinal, produzindo uma grande quantidade de ácido lático e ácidos graxos voláteis. Os produtos da fermentação bacteriana associados aos resíduos alimentares não digeridos e não absorvidos, bem como os minerais incrementam a osmolalidade do conteúdo intestinal, levando a uma baixa reabsorção de água e num contínuo influxo de água para o lúmen intestinal, resultando em diarréia. Já Ball \& Aherne (1981) verificaram que leitões alimentados com uma ração semi-complexa 
apresentaram diarréia significativamente mais severa do que aqueles que receberam ração simples, entendendo assim que a adoção de uma dieta mais digestível não reduz o quadro de diarréia de leitões recém-desmamados.

O uso de 2500 a $3000 \mathrm{ppm}$ de $\mathrm{Zn}$ na forma de óxido de $\mathrm{Zn}(\mathrm{ZnO})$ é um eficaz agente controlador de diarréia pósdesmame (Bertol \& Brito, 1995; Lima et al., 1994 e Menten et al., 1992). O modo de ação do $\mathrm{Zn}$ como anti-diarréico deve-se ao efeito inibitório do íon $\mathrm{Zn}$ sobre a Escherichia coli (Lima et al., 1994), uma vez que Brito et al. (1993) verificaram "in vitro" que o óxido de $\mathrm{Zn}$ apresenta um efeito inibidor sobre amostras de E. coli, envolvidas em diarréia pós desmame. Kasahara \& Anraku (1972; 1974), também, observaram que o íon $\mathrm{Zn}$ apresenta um efeito inibitório sobre o sistema oxidase da cadeia respiratória das membranas vesiculares de E. coli.

A restrição alimentar é uma prática utilizada na prevenção de diarréia de leitões desmamados precocemente. Bertol \& Brito (1995) observaram que este manejo é mais efetivo no controle de diarréia do que o uso de rações à vontade suplementadas com doses elevadas de $\mathrm{Cu}$ ou $\mathrm{Zn}$. Já Hill et al. (1996) observaram que a inclusão de elevadas doses do $\mathrm{Cu}$ e (ou) do $\mathrm{Zn}$ em dietas de leitões recém-desmamados resultou em fezes firmes e mais escuras, principalmente com o uso do cobre. 


\section{3 . MATERIAL E MÉTODOS}

O experimento foi conduzido nas instalações experimentais do Departamento de Produção Animal da ESALQUSP - Piracicaba - SP. Foram utilizados 80 leitões, provenientes da Granja Santo André, Capivari - SP, sendo 40 machos castrados e 40 fêmeas, obtidos do cruzamento de fêmeas Agroceres Fl com machos terminadores Agroceres 405. Os leitões foram desmamados aos $21 \pm 2$ dias de idade e peso médio de $6,85 \mathrm{~kg}$ e transferidos imediatamente para as instalações experimentais, dando-se início ao experimento. Durante o período de aleitamento, a partir de 5 dias antes do desmame, os leitões tiveram acesso a uma ração baseada em milho, farelo de soja, soro de leite em pó e açúcar, contendo $2500 \mathrm{ppm}$ de $\mathrm{Zn}$ na forma de óxido de zinco. O experimento foi conduzido por quatro semanas, tendo os leitões atingido $18,67 \mathrm{~kg}$ de peso médio ao final do período experimental. Dois animais foram eliminados no decorrer do experimento.

Antes do alojamento dos animais, a creche foi limpa e desinfetada, permanecendo vazia por um período aproximado de 90 dias. As instalações experimentais consistiram de uma sala de creche com 20 gaiolas metálicas suspensas com dimensões 1,20 $x 1,50 \mathrm{~m}$ cada uma. As gaiolas eram providas de comedouro automático e bebedouro tipo chupeta e o piso era parcialmente vazado, sendo que a área adjacente ao comedouro era compacta e a 
área adjacente ao bebedouro era metálica e vazada. As gaiolas eram, também, providas de aquecimento complementar, proporcionado por lâmpadas infra-vermelhas de $250 \mathrm{~W}$, que foram mantidas ligadas com a finalidade de manter a temperatura média no interior da sala em torno de $32^{\circ} \mathrm{C}$ nas primeiras duas semanas e $28^{\circ} \mathrm{C}$ nas semanas subsequentes.

O período experimental consistiu de duas fases, sendo uma de 01 a 14 dias e outra de 15 a 28 dias. Os tratamentos foram de 5 dietas, sendo uma ração basal (Tratamento CONT). A esta ração basal foi adicionado $200 \mathrm{ppm}$ de $\mathrm{Cu}$ na forma de sulfato de $\mathrm{Cu}$ penta-hidratado (Tratamento $200 \mathrm{SUL}$ ) ou níveis crescentes de 50,100 e $150 \mathrm{ppm}$ de $\mathrm{Cu}$ na forma de citrato cúprico, tratamentos 50 CIT, 100 CIT e 150 CIT, respectivamente. Nos primeiros 14 dias do período experimental todas as rações continham 2500 ppm de $Z n$ na forma de óxido de zinco.

Nas duas fases do período experimental, as dietas foram formuladas para atingir o mínimo ou exceder os níveis recomendados pelo NRC (1998). A composição percentual das rações experimentais, bem como os nutrientes calculados de cada uma delas estão apresentados na Tabela 1. Estas rações foram preparadas em um misturador vertical, sendo $150 \mathrm{~kg}$ por tratamento na primeira fase (1-14 dias) e $300 \mathrm{~kg}$ por tratamento na segunda fase (15-28 dias). As inclusões dos diferentes níveis do sulfato de cobre penta-hidratado $\left(\mathrm{CuSO}_{4} .5 \mathrm{H}_{2} \mathrm{O}\right)$ e do citrato cúprico $\left(\mathrm{C}_{6} \mathrm{H}_{4} \mathrm{CuO}_{7}\right)$ deram-se pela substituição ao caulim existente na prémistura, que por sua vez foram processadas num misturador em Y junto com os demais ingredientes da pré-mistura.

O experimento foi em blocos casualizados com 4 repetições por tratamento e com 4 leitões ( 2 machos castrados e 2 fêmeas) por unidade experimental. Após a chegada na creche 
Tabela 1-Composição percentual e valores calculados das dietas basais

\begin{tabular}{|c|c|c|}
\hline Ingredientes & $\begin{array}{c}\text { Ração Basal l } \\
(1-14 \text { dias })\end{array}$ & $\begin{array}{l}\text { Ração Basal } 2 \\
(15-28 \text { dias })\end{array}$ \\
\hline Milho & 52,88 & 53,71 \\
\hline Farelo de soja & 21,33 & 23,66 \\
\hline Plasma de sangue & 2,00 & 1,50 \\
\hline Açúcar & 4,00 & 4,00 \\
\hline Calcário & 1,11 & 1,00 \\
\hline Fosfato bicálcico & 1,33 & 1,33 \\
\hline Sal moído & 0,30 & 0,30 \\
\hline Lactose & 5,55 & 5,00 \\
\hline Leite em pó desnatado & 10,00 & 8,00 \\
\hline Pré-mistura & 1,50 & 1,50 \\
\hline Caulim & $(0,25)$ & $(0,25)$ \\
\hline Milho, veículo & $(0,36)$ & $(0,73)$ \\
\hline Aroma de baunilha & $(0,04)$ & $(0,04)$ \\
\hline Óxido de zinco & $(0,34)$ & --.-- \\
\hline Cloreto de colina, $50 \%$ & $(0,05)$ & $(0,05)$ \\
\hline $\mathrm{L}-1$ isina, $\mathrm{HCl}^{\mathrm{a}}$ & $(0,25)$ & $(0,22)$ \\
\hline Antioxidante & $(0,01)$ & $(0,01)$ \\
\hline Suplem.Vitamínico-mineral b & $(0,20)$ & $(0,20)$ \\
\hline Valores Calculados: & & \\
\hline Energia metaboliz., kcal/kg & 3300 & 3300 \\
\hline Proteina bruta, $\%$ & 19,50 & 19,50 \\
\hline Lisina, \% & 1,35 & 1,30 \\
\hline Cálcio, \% & 0,95 & 0,90 \\
\hline Fósforo disponível, $\%$ & 0,46 & 0,44 \\
\hline Fósforo total, \% & 0,59 & 0,58 \\
\hline
\end{tabular}

${ }^{a}$ Contendo $78 \%$ L-lisina

${ }^{b}$ Suprindo as seguintes quantidades por kg de ração: Vit. A, 8000 UI; Vit. $\mathrm{D}_{3}, 1500$ UI: Vit. E, $18 \mathrm{mg}$; Vit. $\mathrm{K}_{3}, 2 \mathrm{mg}$; Vit. $\mathrm{B}_{1}, 1,5 \mathrm{mg}$; Vit. $\mathrm{B}_{2}, 4 \mathrm{mg}$; Vit $\mathrm{B}_{6}, 1,5 \mathrm{mg}$; Vit $\mathrm{B}_{12}, 18 \mathrm{mcg}$; Ácido Fólico, $0,4 \mathrm{mg}$; Biotina, $0,1 \mathrm{mg}$; Ácido Pantotênico, $15 \mathrm{mg}$; Niacina, $30 \mathrm{mg}$; Selênio, 0,120 mg; Manganês, 45 $\mathrm{mg}$; Ferro, $88 \mathrm{mg}$; Cobre, $15 \mathrm{mg}$; Iodo, $1 \mathrm{mg}$; Zinco, $80 \mathrm{mg}$ 
experimental, os animais foram pesados e distribuídos aos blocos de acordo com o peso inicial, sexo e a ninhada de origem.

Os leitões receberam ração e água à vontade durante todo o período experimental. Foram realizadas semanalmente as pesagens individuais dos leitões e os registros do consumo de ração no período, calculando-se para os períodos intermediários e para o período total os dados relativos ao ganho diário médio de peso (GDP), consumo diário médio de ração (CDR) e conversão alimentar média (CA).

Os dados de performance foram submetidos à análise de variância PROG GLM (General Linear Models) do SAS (Statistical Analysis System, 1993). Além disso, os graus de liberdade do fator nível de $\mathrm{Cu}$ orgânico na ração foi decomposto em seus componentes individuais de regressão, através dos polinômios ortogonais. Adicionalmente, as médias de todos os cinco tratamentos foram, também, comparadas pelo teste de Tukey a $5 \%$ de probabilidade. 


\section{RESULTADOS E DISCUSSÃO}

As médias das características de performance dos leitões em recria alimentados com ração contendo sulfato de cobre e níveis crescentes de citrato cúprico, referentes aos períodos experimentais de 1 a 14 dias, 15 a 28 e 1 a 28 dias, são apresentados, respectivamente, nas Tabelas 2,3 e 4 . Os resultados detalhados por semana se encontram nas Tabelas A1, A2, A3, A4, A5, A6, A7, A8 e A9 do Apêndice. Foi tomado o período inicial de duas semanas porque esta fase pós-desmame é crítica ao desempenho dos leitões e, consequentemente, é quando a resposta aos promotores de crescimento normalmente é mais pronunciada (Menten, 1995). Neste período foi incluído 2500 ppm de $\mathrm{Zn}$ com a finalidade de evitar a ocorrência de um possível quadro de diarréia fisiológica. Considerando que elevados níveis de $\mathrm{Zn}$ na dieta podem afetar a resposta do $\mathrm{Cu}$ como agente promotor do crescimento, foi avaliado o período de 15 a 28 dias, onde, nesta fase, a inclusão do mineral $\mathrm{Zn}$ atingiu apenas a exigência nutricional. A avaliação do período de 1 a 28 dias representa o desempenho dos leitões na fase de creche.

Para as três variáveis analisadas não foram observadas diferenças significativas $(P>0,05)$ entre os tratamentos em quaisquer fases do período experimental. 
Tabela 2- Médias das características de performance dos leitões em recria alimentados com ração contendo sulfato de cobre e níveis crescentes de citrato cúprico - 1 a 14 dias.

\section{Tratamentos}

\begin{tabular}{lcccccc}
\hline & \multicolumn{7}{c}{ Tratamentos } & \\
\cline { 2 - 6 } & & & & & \\
CONT & 200 & 50 & 100 & 150 & CV $^{\text {a }}$ \\
Item & & SUL & CIT & CIT & CIT & $\%$ \\
\hline No.de animais & 16 & 15 & 16 & 15 & 16 & \\
GDP (g) & 311 & 281 & 311 & 243 & 287 & 14,54 \\
CDR (g) & 458 & 446 & 491 & 384 & 451 & 12,75 \\
CA & 1,48 & 1,65 & 1,58 & 1,54 & 1,57 & 12,83 \\
\hline a Coeficiente de Variac̃o, \% & & & & &
\end{tabular}

Tabela 3- Médias das características de performance dos leitões em recria alimentados com ração contendo sulfato de cobre e níveis crescentes de citrato cúprico- 15 a 28 dias.

\begin{tabular}{lcccccc}
\hline & \multicolumn{5}{c}{ Tratamentos } & \\
\cline { 2 - 6 } & & & & & \\
CONT & 200 & 50 & 100 & 150 & CV $^{\text {a }}$ \\
Item & & SUL & CIT & CIT & CIT & $\%$ \\
\hline No. de animais & 16 & 15 & 16 & 15 & 16 & \\
GDP (g) & 549 & 601 & 568 & 520 & 547 & 8,11 \\
CDR (g) & 941 & 1009 & 954 & 884 & 955 & 8,53 \\
CA & 1,72 & 1,71 & 1,68 & 1,68 & 1,75 & 9,22 \\
\hline
\end{tabular}

${ }^{a}$ Coeficiente de Variação, \% 
Tabela 4- Médias das características de performance dos leitões em recria alimentados com ração contendo sulfato de cobre e níveis crescentes de citrato cúprico - 1 a 28 dias.

\begin{tabular}{lcccccc}
\hline & \multicolumn{5}{c}{ Tratamentos } & \\
\cline { 2 - 6 } & & & & & \\
CONT & 200 & 50 & 100 & 150 & CV $^{\text {a }}$ \\
Item & & SUL & CIT & CIT & CIT & $\%$ \\
\hline No. de animais & 16 & 15 & 16 & 15 & 16 & \\
GDP (g) & 430 & 441 & 440 & 382 & 417 & 8,35 \\
CDR (g) & 700 & 727 & 722 & 634 & 703 & 9,23 \\
CA & 1,62 & 1,68 & 1,64 & 1,63 & 1,68 & 6,41 \\
\hline
\end{tabular}

As diferenças não significativas entre as médias dos tratamentos podem estar relacionadas com o tipo de dieta utilizado. Resultados semelhantes foram obtidos por Edmonds et al. (1985) e Smith et al. (1997), que em função da maior digestibilidade da dieta, menor foi o efeito do $\mathrm{Cu}$ como agente promotor do crescimento para leitões. Zhou et al. (1994a) sugeriram que o maior efeito do $\mathrm{Cu}$ como agente promotor do crescimento deve-se ao estímulo de consumo de alimento. O mesmo efeito é obtido com o uso de dietas complexas (Bayley \& Carlson, 1970; Lepine et al., 1991; Meade et al., 1969; Okai et al., 1976 e Zimmerman \& Khajarern, 1973).

Roura et al. (1992) afirmaram que as contaminações microbianas, decorrentes do uso de instalações inadequadas e com pouca higiene, podem levar os animais a um quadro denominado de "estresse imunológico", onde os nutrientes destinados ao crescimento de órgãos e tecidos são desviados em favor da ativação 
do sistema imunológico, sendo que uma das formas de atuação dos agentes antimicrobianos como promotores do crescimento vem a ser a redução deste quadro. Apesar das muitas teorias do modo de ação do $\mathrm{Cu}$ na melhoria do desempenho de aves e suínos, há fortes evidências de que elevadas doses deste mineral atuam sobre os microrganismos (Bunch et al., 1961; Elliot \& Amer, 1973; Menten, 1995 e Shurson et al., 1990). Os resultados deste experimento podem estar relacionados com este mecanismo de ação. O período de 90 dias de vazio sanitário, a excelente qualidade das instalações, bem como as práticas de desinfecção adotadas podem ter gerado um ambiente com baixa concentração de microrganismos patogênicos. A falta de desafio microbiano pode ter reduzido a ativação do sistema imunológico e, consequentemente, o $\mathrm{Cu}$ não conseguiu expressar sua capacidade promotora do crescimento.

Considerando a fase de 1 a 14 dias observa-se que o GDP do tratamento 50 CIT foi semelhante ao CONT. Mesmo não sendo estatisticamente significativo $(P>0,05)$, o GDP dos demais tratamento foram inferiores ao CONT sendo $-9,65 \%$ com o uso de 200 SUL, $-21,86 \%$ com 100 CIT e $-7,72 \%$ com 150 CIT. A CA do tratamento 200 SUL foi $11,48 \%$ pior que o CONT. Os demais tratamentos também apresentaram uma pior CA quando comparadas ao CONT na proporção de $-6,75 \%$ para 50 CIT, $-4,05 \%$ para 100 CIT e $-6,08 \%$ para 150 CIT. Foi observado, também, que todos os tratamentos, exceto $50 \mathrm{CIT}$, apresentaram menor CDR comparados ao CONT, sendo $-2,62 \%$ com o uso de 200 SUL e $-16,15 \%,-1,53 \%$ para os respectivos 100 CIT e 150 CIT.

A inclusão de $2500 \mathrm{ppm}$ de $\mathrm{Zn}$ em todos os tratamentos da fase de 1 a 14 dias proporcionou resultado próximo aos obtidos por Hill et al. (1996), Ritchie et al. (1963) e Smith et al.(1997), onde o uso conjunto de níveis elevados de $\mathrm{Cu}$ e $\mathrm{Zn}$ não 
propiciaram tanta eficiência no desempenho de leitões quanto o uso exclusivo do $\mathrm{Zn}$ como agente promotor do crescimento. Smith et al. (1997) estabeleceram a hipótese de que a inclusão de até $3000 \mathrm{ppm} \mathrm{de} \mathrm{Zn}$, em dietas com $250 \mathrm{ppm} \mathrm{Cu}$ para leitões, induz a redução do $\mathrm{Cu}$ livre no organismo animal em decorrência do aumento da quantidade de metalotioneína corpórea. A redução do $\mathrm{Cu}$ livre no organismo e a implantação de um possível imbalanço $\mathrm{Zn}: \mathrm{Cu}$ inibem o metabolismo de carboidratos e lipídios, resultando numa redução da performance dos animais.

No intervalo de 15 a 28 dias também não foram observadas diferenças significativas $(P>0,05)$ no desempenho dos animais submetidos aos diversos tratamentos. Porém, para a variável GDP, o tratamento 200 SUL foi numericamente superior $(9,47 \%)$ ao CONT. Para os níveis crescentes de citrato cúprico observou-se que o tratamento 50 CIT foi superior ao CONT, bem como aos demais níveis de citrato. O CDR também foi mais evidente para o tratamento $200 \mathrm{SUL}$, sendo $7,22 \%$ superior ao tratamento CONT. Para a variável CA, observa-se neste período que as obtidas nos tratamentos 50 CIT e 100 CIT foram melhores que o CONT bem com aos demais tratamentos.

Nesta fase, de 15 a 28 dias do período experimental, pode-se verificar que o efeito promotor do crescimento do cobre varia de acordo com as fontes e níveis utilizados (Baker et al., 1991; Cromwell et al., 1989 Pesti \& Bakalli, 1996 e Zhou et al., 1994). A eficiência do sulfato de $\mathrm{Cu}$ é muito bem documentada na literatura conforme observaram Cromwell et al. (1989). Os resultados desta fase não estão de acordo com aqueles obtidos por Pesti \& Bakalli (1996), onde estes autores verificaram que o citrato cúprico é mais eficiente que o sulfato de cobre penta-hidratado como agente promotor do crescimento para frangos de corte. 
Mesmo não havendo diferença estatística $(P>0,05)$ para o período de 1 a 28 dias, observa-se que o GDP e CDR dos tratamentos 200 SUL e 50 CIT foram numericamente superiores aos demais. Comparando os níveis crescentes de citrato cúprico, verificou-se uma melhor resposta para o tratamento 50 CIT, seguido do 150 CIT, sendo que o pior desempenho deu-se com o uso de $100 \mathrm{CIT}$. Estes resultados assemelham-se aos obtidos por Pesti \& Bakalli (1996), onde os autores, avaliando níveis crescentes de citrato cúprico em dietas para frangos de corte, encontraram uma melhor resposta no GDP com $125 \mathrm{ppm}$ de $\mathrm{Cu}$, sendo que o efeito de toxicidade deu-se com $250 \mathrm{ppm}$ de $\mathrm{Cu}$. Já numa segunda fase, avaliando o mesmo citrato cúprico, verificaram que $63 \mathrm{ppm}$ de $\mathrm{Cu}$ foi significativamente melhor que $125 \mathrm{ppm}$ de $\mathrm{Cu}$. Estas observações possibilitaram a formulação da hipótese de que os níveis de eficiência e toxicidade do citrato cúprico estão bem próximos e aparentemente o $\mathrm{Cu}$ na forma de citrato cúprico apresenta maior eficácia a baixos níveis quando comparado com o uso de sulfato de cobre penta-hidratado. 


\section{5 . CONCLUSÃO}

Baseando-se nos resultados obtidos neste experimento, observa-se que não ficou evidenciada a atividade promotora do crescimento dos altos níveis de $\mathrm{Cu}$ orgâncio (citrato cúprico) ou inorgânico (sulfato de $\mathrm{Cu}$ penta-hidratado) em leitões recémdesmamados alimentados com ração complexa. 


\section{REFERÊNCIAS BIBLIOGRÁFICAS}

AMER, M.A.; ELLIOT, J.I. Effects of supplemental dietary copper on glyceride distribuition in the backfat of pigs. Canadian Journal Animal Science, v. 53, n.1, p.147-152, 1973.

BAKALli, R.; PESTI, G.M.; RAGLAND, W.L.; KONJUFCA, V. Dietary copper in excess of nutritional requeriment reduces plasma and breast muscle cholesterol of chickens. Poultry Science, v.74, n.2, p.360-365, 1995.

BAKER, D.H.; ODLE, J.; FUNK, M.A.; WIELAND, T.M. Research note: bioavailability of copper in cupric oxide, cuprous oxide and in a copper-lysine complex, Poultry Science, v.70, n.1, p. 177-179, 1991.

BALL, R.O.; AHERNE, F.X. Influence of dietary nutrient density, level of feed intake and weaning age on young pigs.i. performance and body composition, Canadian Journal Animal Science, v.67, n.4, p.1093-1103, 1987.

BARBER, R.S.; BRAUDE, R.; MITChelL, K.G. Antibiotic and copper supplements for fattening pigs. Britsh Journal of Nutrition, v.09, n.4, p.378-386, 1955.

BARBER, R.S.; BRAUDE,R.; MITCHELL, K.G. Further studies on antibiotic, copper and zinc supplements for growing pigs. Britsh Journal of Nutrition, v. 14, p.70-79, 1960. 
BAYLEY, H.S.; CARLSON,W.E. Comparisons of simple and complex diets for baby pigs: effects of form of feedand glucose addition. Journal Animal Science, v. 30, n.1, p.394-401, 1970.

BERTO, D.A.; KRONKA, R.N.; THOMAZ, M.A.; KRONKA, S.N. Efeito do tipo de dieta e do sistema de alimentação na fase inicial sobre o desempenho de leitões. Revista Brasileira de Zootecnia, v.26, n.1, p.144-152, 1997.

BERTOL, T.A.; BRITO, B.G. Efeito de óxido de zinco $x$ sulfato de cobre com ou sem restrição alimentar, sobre desempenho e ocorrência de diarréia em leitões. Revista Brasileira de Zootecnia, v.24, n.2, p.279-288, 1995.

BOTELHO, F.G.A. O zinco como promotor do crescimento de suínos em recria. Piracicaba, 1996. 67p. Dissertação (MS) "Escola Superior de Agricultura "Luiz de Queiroz", Universidade de São Paulo.

BRITO, M.A.V.P.; LIMA, G.J.M.M.; BRITO, J.R.F.; MORES, N. Ação do óxido de zinco sobre amostras de Escherichia coli isoladas de suínos com diarréia pós-desmame. In: CONGRESSO BRASILEIRO DE VETERINÁRIOS ESPECIALISTAS EM SUÍNOS, 6., Goiânia, 1993. Anais. Goiânia, Associação Brasileira dos Veterinários Especialistas em Suínos, 1993, p. 157.

BRITO, B.G.; MORES, N. Fatores de risco que interferem no desempenho dos leitões pós-desmame em granjas suinícolas do sudeste do Paraná. In: REUNIÃo ANUAL DA SOCIEDADE 
BRASILEIRA DE ZOOTECNIA, 29., Lavras, 1992. Anais. Lavras, Sociedade Brasileira de Zootecnia, 1992, p. 368.

BUNCH, R.J.; SPEER, V.C.; HAYS, V.W.; HAWBAKER, J.H. ; CATRON, D.V. Effects of copper sulfate, copper oxide and chlortetracycline on baby pig performance. Journal Animal Science, v.20, n.1, p.723 - 727, 1961.

CERA, K.R.; MAHAN, D.C.; REINHART, G.A. Weekly digestibilities of diets supplementede with corn oil, lard or tallow by weanling swine. Journal Animal Science, v. 66, n.2, p. $1430-1437,1988$.

CERA, K.R., MAHAN, D.C.; REINHART, G.A. Apparent fat digestibilities and performance responses of postweaning swine fed diets supplementede with coconut oil, corn oil or tallow. Journal Animal Science, v. 67, n.4, p. 2040 - 2047, 1989.

CROMWELL, G.L.; STHALY, T.S. ; MONEGUE, H.J. Effects of source and level of copper on performance and liver copper stores in weanling pigs. Journal Animal Science, v.67, n.6, p. $2996-3002,1989$.

CROMWELL, G.L. Antimicrobial agents. In: MILlER, E.R.;UllReY, D.E.; LEWIS, A.J. (ed.) Swine Nutrition. Butterworth-Heineman, Stoneham, MA., 1991. Cap.19, p.297 314.

DOVE, C.R.; HAYDON, K.D. The effect of copper addition to diets with various iron levels on the performance and hematology of 
weanling swine. Journal Animal Science, v.69, n.3, p. 2013 2019. 1991 .

DOVE, C.R.; HAYDON, K.D. The effect of copper and fat addition to the diets of weanling swine on growth performance and serum fatty acids. Journal Animal Science, v.70, n.1-3, p. 805 $-810,1992$.

DOVE, C.R. The effect of copper level on nutrient utilization of weanling pigs. Journal Animal Science, v.73, n.1, p.166 $171,1995$.

EDMONDS, M.S.; IZQUIERDO,O.A.; BAKER, D.H. Feed additive studies with newly weaned pigs: efficacy of supplemental copper, antibiotics and organic acids. Journal Animal Science, v.60, n.2, p. $462-469,1985$.

ELLIOT, J.I.; AMER, M.A. Influence of level of copper supplement and removal of supplemental copper from the diet on the performance of growing-finishing pigs and accumulation of copper in the liver. Canadian Journal Animal Science, v. 53, n. 1, p. $133-138,1973$.

ETHERIDGE, R.D.; SEERLEY, R.W.; WYATT,R.D. The effect of diet on performance, digestibility, blood composition and intestinal microflora of weaned pigs. Journal Animal Science, v. 58, n.6, p. 1396-1402, 1984 a.

ETHERIDGE, R.D.; SEERLEY, R.W.; HUBER, T.L. The effect of diet on fecal moisture, osmolarity of fecal extracts, products of 
bacterial fermentation and loss of minerals in feces of weaned pigs. Journal Animal Science, v.58, n.6, p.1403-1411, 1984 b.

EWING, H.P.; PESTI, G.M.; BAKALli, R.I.; MENTEN, J.F. Studies on the feeding of cupric sulfate pentahidrate, cupric citrate and copper oxychloride to broiler chickens. Poultry Science, v.77, n.3, p.445-448, 1998.

GIPP, W.F.; POND, W.G.; TASKER, J.; VAN CAMPEN, D.; KROOK, L.; VISEK, J. Influence of level of dietary copper on weight gain, hematology and liver copper and iron storage of young pigs. The Journal of Nutrition, v.103, p. 713-719, 1973.

HANRAHAN, T.J.; O'GRADY, J.T. Copper supplementation of pig diets: the effects of protein level and zinc supplementation of the response to added copper. Animal Prodution, Edinburg, v. 10, p. $423-432,1968$.

HAWBAKER, J.A.; SPEER, V.C.; HAYS, V.W.; CARON, D.V. Effect of copper sulfate and other chemotherapeutics in GROWING SWINE RAIONS. Journal Animal Science, v.20, n. 1, p. $163-165,1961$.

HILL, G.M.; CROMWELL, G.L., CRENSHAW, T.D.; EWAN, R.C.; KNABE, D.A.; LEWIS, A.J.; MAHAN, D.C.; SHURSON, G.C.; SOUTHERN, L.L.; VEUM, T.L. Impact of pharmacological intakes of zinc and (or) copper on performance of weanling pigs. Journal Animal Science, v.74, n.1, p.181-181,1996. /Resumo 300 em Abstracts. 
HOWARD, K.A.; FORSYTH, D.M.; CLINE, T.R. The effect of an adaptation period to soybean oil additions in the diets of young pigs. Journal Animal Science, v.68, n.2, p.678-683, 1990.

KASAHARA, M.; ANRAKU, Y. Succinate and NADH oxidase sysems of Escherichia coli manbrane vesicles. Mechanism of selective inhibition of the systems by zinc ions. Journal of Biochemistry, Tokyo, v.76, n.5, p. 967-976, 1974.

KASAHARA, M.; ANRAKU, Y. Inhibition of the respiratory chain of Escherichia coli by zinc ions. Journal of Biochemistry, Tokyo, v.72, n.3, p.777-781, 1972.

KONJUFCA, V.H.; PESTI, G.M.; BAKALLI, R.I. Modulation of cholesterol levels in broiler meat by dietary garlic and copper. Poultry Science, v.76, n.9, p. 1264-1271, 1997.

KYRIAKIS, S.C. New aspects of the prevention and/or treatment of the major stress induced diseases of the early weaned piglet. Pig News \& Information, Shinfield, v.10, n.2, p.177-181, 1989.

LAWRENCE, N.J.; MAXWELL, C.V. Effects of dietary fat source and level on the performance of neonatal and early weaned pigs. Journal Animal Science, vol. 57, n.2, p.936 - 942, 1983.

LEDOUX, D.R.; HENRY, P.R.; AMMERMAN, C.B.; RAO, P.V. ; MILES, R.D. Estimation of the relative bioavailability of inorganic copper sources for chicks using tissue uptake of copper. Journal Animal Science, v.69, n.1, p.215-222, 1991. 
LE MIEUX, F.M.; SOUTHERN, L.L.; WARD, T.L.; BIDNER, T.D. Growth performance of weanling pigs fed excess dietary zinc. Journal of Animal Science, v. 74, n.1, p172-172,1996. /Resumo 249 em Abstracts.

LEPINE, A.J.; MAHAN, D.C. ; CHUNG, Y.K. Growth performance of weanling pigs fe corn-soybean meal diets with or without dried whey at various 1-lysine-HCl levels. Journal Animal Science, v.69, n. 3, p.2026 - 2032, 1991.

LIMA, G.J.M.M.; MORAES, N.; FIAlHo, F.B.; BRITO, A.A.V.P.; GOMES, P.C. Efeito do período de suplementação de zinco na dieta sobre o desempenho de suínos desmamados. Revista da Sociedade Brasileira de Zootecnia, v.23, n.6, p.949-958, 1994.

McDOWELL, L.R. Minerals in animal and human nutrition. San Diego, Califórnia : Ed Academic Press Inc., 1992. Cap.8, p. 176-202: Copper and molybdenum.

MEADE, R.J.; RUST, J.W.; MILLER, K.P.; HANKE, H.E.; GRANT, R.S.; VERMEDAHL, L.D.; WASS, D.F.; HANSON, L.E. Effects of protein level sequence and kind of starter on rate and efficiency of gain of growing swine, and on carcass characteristics. Journal Animal Science, v.29, n.1, p.303$319,1969$.

MENTEN, J.F.M. Eficácia, efeito sinérgico e modo de ação de agentes antimicrobianos como promotores do crescimento de suínos. Piracicaba, 1995. 106p. Tese (Livre Docência)-Escola 
Superior de Agricultura "Luiz de Queiroz", Universidade de São Paulo.

MENTEN, J.F.M.; MIYADA, V.S.; CITRONI, A.R. Suplementação de alto nível de zinco na dieta de leitões. In: REUNIÃo ANUAL DA SOCIEDADE BRASILEIRA DE ZOOTECNIA, 29., Lavras, 1992. Anais. Lavras, Sociedade Brasileira de Zootecnia, 1992, p.368.

MENTEN, J.F.M.; AMES, N.K.; KU, P.K.; MILLER, E.R. Effects of hig dietary copper on blood and intestinal variables of starter pigs. Journal Animal Science. v.66,n.1, 1988. /Resumo 330 em Abstract. 1988.

MILES, R.D.; O'KEEFE, S.F.; HENRY, P.R.; AMMERMAN, C.B. LUO, X.G. The effect of dietary supplementation with copper sulfate or tribasic copper chloride on broiler performance, relative copper bioavailability, and dietary prooxidant activity. Poultry Science, v.77, n.3, p.416-425. 1998.

MIYADA, V.S.; MENTEN, J.F.M.; BEDUSCHI NETO, F.; SPERL, E.; FRANÇA. D. Níveis de zinco dietético suplementar como promotor de crescimento de leitões na fase de creche. In: REUNIÃO ANUAL DA SOCIEDADE BRASILEIRA DE ZOOTECnIA, 31., Viçosa, 1994. Anais. Viçosa, Sociedade Brasileira de Zootecnia, 1994.p.

MIYADA, V.S.; MENTEN, J.F.M; PACKER, I.U.; LAVORENTI, A. Avaliação de níveis crescentes de zinco dietético suplementar como promotor do crescimento de leitões na fase 
de creche. In: REUNIÃO ANUAL DA SOCIEDADE RASILEIRA DE ZOOTECNIA, 30., Rio de Janeiro, 1993. Anais. Rio de Janeiro, Sociedade Brasiliera de Zootecnia, 1993. p. 383 .

MUIRHEAD, S. Future goal is definition of "prudent use for antimicrobials". Feedstuffs, v.70, n.17, p.1-5, April, 1998.

MULLER, E.R. Physiological relationships between microbiological status and dietary copper levels in the pig. Journal Animal Science, v.68, n.2, p. 1061-1071, 1990.

MYRES, A.W.; BOWLAND, J.P. Effects of environmental temperature and dietary copper on growth and lipid metabolism in pigs. I. growth, carcass quality, and tissue copper levels. Canadian Journal of Animal Science, v. 53, n.1, p.115-120, 1973.

NATIONAL RESEARCH COUNCIL - NRC. Subcommittee on swine nutrition. Committee on animal nutrition. Nutrient Requeriments of Swine. 10 ed. Washington, National Academy Press, p. 52, 1998.

OKAI, D.B.; AHERNE, F.X.; HARDIN, R.T. Effects of creep and stater composition on feed intake and performance of young pigs. Canadian Journal of Animal Science., v.56, n.3, p.573$586,1976$.

PESTI G.; BAKALLI, R.I. Studies on the feeding of cupric sulfate pentahydrate and cupric citrate to broiler chickens. Poultry 
Science, v. 75, n.9, p.1086-1091, 1996.

POSSOBON, R.M. O cobre como estimulante do crescimento de suínos em recria. Piracicaba, 1990. 55p. Dissertação, (MS) Escola Superior de Agricultura "Luiz de Queiroz", Universidade de São Paulo.

RADECKI, S.V.; AMES, N.K.; MILlER, E.R.; YOKOYAMA, M.T. Influence of copper sulfate, carbadox or chlortetracycline supplementation on ammonia and volatile fatty acid production, urea hydroysis, and bacterial counts in the jejunum and colon of cannulated young pigs. Research Report 502-Michigan State University Agricultural Experiment Station, East Lansing, MI. p. $128-134,1990$.

RITCHIE, H.D.; LUECKE, R.W.; BALTZER,B.V.; MILLER, E.R. ULLREY, D.E.; HOEFFER, J.A. Copper and zinc interrelationships in the pig. Journal Nutrition, v.79, p. 117 $123,1963$.

ROOF, M.D.; MAHAN, D.C. Effect of carbadox and various dietary copper levels for weanling swine. Journal Animal Science, v.55, n.3, p. $1109-1117,1982$.

ROURA, E.; HOMEDES,J.; KLASING,K. Prevention of immunologic stress contributes to the growth permitting ability of dietary antibiotics in chicks. Journal Nutrition, v. 122 , n.12, p. 2383-2390, 1992 .

SHURSON, G.C.; KU, P.K.; WAXLER, G.L.; YOKOYAMA, M.T.; 
MILLER, E.R. Physiological relationships between microbiological status and dietary copper levels in the pig. Journal Animal Science, v.68, n.2, p. 1061-1071, 1990.

SMITH, J.W.; TOKACH, M.D.; GOODBAND, R.D.; NELSSEN, J.L.; RICHERT, B.T. Effects of the interrelationship between zinc oxide and copper sulfate on growth performance of earlyweaned pigs. Journal Animal Science, v.75, n.7, p.1861 $1866,1997$.

STAHLY T.S.; CROMWELL, G.L.; MONEGUE, H.J. Effects of the dietary inclusion of copper and (or) antibiotics on the performance of weanling pigs. Journal Animal Science, v.51, n. 3, p.1347-1351, 1980 .

THE MERCK INDEX, Nova Jersey, Merck \& Co., Inc., 10 ed. 1983.

UNDERWOOD, E.J. Trace elements in human and animal nutrition. Fourth Edition. New York, Ed Academic Press, 1977. cap. 57, p71-75: Copper.

WALLACE, H.D. Biological responses to antibacterial feed additives in diets of meat producing animals. Journal Animal Science, v.31, n.1, p.1118-1126, 1970.

VISEK, W.J. The mode of growth promotion by antibiotics. Journal Animal Science, v.46, n. 3, p.1447 - 1469, 1978.

YEN, J.T.; NIENABER, J.A. Effects of high-copper feeding on 
portal ammonia absorption and on oxygen consumption by portal vein-drained organs and by the whole animal in growing pigs. Journal Animal Science, v.71, n.8, p.2157-2163, 1993.

ZHOU, W.; KORNEGAY, E..; LAAR, V.H; SWINKELS J.W.G.M.; WONG, E.A.;LINDEMANN, M.D. The role of feed consumption and feed efficiency in copper- stimulated growth. Journal Animal Science, v.72, n.9, p.2385-2394, 1994 a.

ZHOU, W.; KORNEGAY, E.T.; LINDEMANN, M.D.; SWINKELS J.W.G.M.; WELTEN, M.K.; WONG, E.A. Stimulation of growth by intravenous injection of copper in weanling pigs. Journal Animal Science, v. 72, n.9, p. $2395-2403,1994$ b.

ZIMMERMAN, D.R.; KHAJARERN, S. Starter protein nutrition and compensatory responses in swine. Journal Animal Science, v.36, n.1, p.189-194, 1973. 


\section{APÊNDICE}


Tabela A1. Resultados de performance dos leitões em recria na primeira semana experimental ( 1 a 7 dias).

\begin{tabular}{|c|c|c|c|c|c|c|}
\hline \multirow[b]{2}{*}{ Item ${ }^{a}$} & \multirow[b]{2}{*}{ Bloco } & \multicolumn{5}{|c|}{ Tratamentos } \\
\hline & & CONT & $200 \mathrm{SUL}$ & 50CIT & $100 \mathrm{CIT}$ & $150 \mathrm{CIT}$ \\
\hline \multirow{5}{*}{ GDP, $\mathrm{g}$} & 1 & 193 & 207 & 260 & 161 & 210 \\
\hline & 2 & 142 & 196 & 250 & 86 & 246 \\
\hline & 3 & 210 & 171 & 196 & 200 & 210 \\
\hline & 4 & 310 & 246 & 192 & 146 & 178 \\
\hline & Média & 214 & 205 & 225 & 151 & 211 \\
\hline \multirow{5}{*}{ CDR, g } & 1 & 264 & 252 & 372 & 236 & 300 \\
\hline & 2 & 189 & 257 & 311 & 164 & 317 \\
\hline & 3 & 304 & 232 & 264 & 261 & 282 \\
\hline & 4 & 343 & 314 & 289 & 175 & 246 \\
\hline & Média & $275^{\circ}$ & 264 & 309 & 209 & 286 \\
\hline \multirow{5}{*}{$\mathrm{CA}$} & 1 & 1.37 & 1.71 & 1.43 & 1.47 & 1.43 \\
\hline & 2 & 1.33 & 1.31 & 1.24 & 1.71 & 1.29 \\
\hline & 3 & 1.44 & 1.35 & 1.35 & 1.31 & 1.34 \\
\hline & 4 & 1.11 & 1.27 & 1.50 & 1.19 & 1.38 \\
\hline & Média & 1.31 & 1.41 & 1.38 & 1.42 & 1.36 \\
\hline
\end{tabular}


Tabela A2. Resultados de performance dos leitões em recria na segunda semana experimental ( 8 a 14 dias).

\begin{tabular}{|c|c|c|c|c|c|c|}
\hline \multirow[b]{2}{*}{ Item ${ }^{a}$} & \multirow[b]{2}{*}{ Bloco } & \multicolumn{5}{|c|}{ Tratamentos } \\
\hline & & CONT & $200 \mathrm{SUL}$ & $50 \mathrm{CIT}$ & $100 \mathrm{CIT}$ & $150 \mathrm{CIT}$ \\
\hline \multirow{5}{*}{ GDP, $\mathrm{g}$} & 1 & 403 & 336 & 382 & 368 & 385 \\
\hline & 2 & 357 & 396 & 400 & 260 & 350 \\
\hline & 3 & 389 & 389 & 443 & 421 & 360 \\
\hline & 4 & 482 & 311 & 364 & 296 & 360 \\
\hline & Média & 408 & 358 & 397 & 336 & 364 \\
\hline \multirow{5}{*}{ CDR, $\mathrm{g}$} & 1 & 628 & 662 & 714 & 414 & 632 \\
\hline & 2 & 539 & 618 & 632 & 572 & 618 \\
\hline & 3 & 664 & 564 & 650 & 704 & 600 \\
\hline & 4 & 732 & 668 & 696 & 493 & 614 \\
\hline & Média & 641 & 628 & 673 & 546 & 616 \\
\hline \multirow{5}{*}{$\mathrm{CA}$} & 1 & 1.56 & 2.04 & 1.87 & 1.13 & 1.64 \\
\hline & 2 & 1.51 & 1.56 & 1.58 & 1.94 & 1.76 \\
\hline & 3 & 1.71 & 1.45 & 1.47 & 1.67 & 1.66 \\
\hline & 4 & 1.52 & 2.15 & 1.91 & 1.66 & 1.71 \\
\hline & Média & 1.57 & 1.80 & 1.71 & 1.60 & 1.69 \\
\hline
\end{tabular}


Tabela A3. Resultados de performance dos leitões em recria na terceira semana experimental ( 15 a 21 dias).

\begin{tabular}{|c|c|c|c|c|c|c|}
\hline \multirow[b]{2}{*}{ Item $^{a}$} & \multirow[b]{2}{*}{ Bloco } & \multicolumn{5}{|c|}{ Tratamentos } \\
\hline & & CONT & $200 \mathrm{SUL}$ & $50 \mathrm{CIT}$ & $100 \mathrm{CIT}$ & $150 \mathrm{CIT}$ \\
\hline \multirow{5}{*}{ GDP, $\mathrm{g}$} & 1 & 485 & 607 & 539 & 525 & 482 \\
\hline & 2 & 460 & 464 & 503 & 439 & 464 \\
\hline & 3 & 417 & 510 & 467 & 461 & 592 \\
\hline & 4 & 492 & 614 & 471 & 478 & 539 \\
\hline & Média & 464 & 549 & 495 & 476 & 519 \\
\hline \multirow{5}{*}{ CDR, g } & 1 & 764 & 876 & 928 & 786 & 878 \\
\hline & 2 & 739 & 854 & 868 & 767 & 804 \\
\hline & 3 & 850 & 828 & 832 & 857 & 961 \\
\hline & 4 & 893 & 964 & 814 & 704 & 843 \\
\hline & Média & 811 & 880 & 860 & 778 & 872 \\
\hline \multirow{5}{*}{$\mathrm{CA}$} & 1 & 1,57 & 1,62 & 1,72 & 1,49 & 1,82 \\
\hline & 2 & 1,61 & 1,84 & 1,73 & 1,61 & 1,73 \\
\hline & 3 & 2,04 & 1,62 & 1,78 & 1,86 & 1,62 \\
\hline & 4 & 1,81 & 1,57 & 1,73 & 1,47 & 1,56 \\
\hline & Média & 1,76 & 1,66 & 1,74 & 1,61 & 1,68 \\
\hline
\end{tabular}


Tabela A4. Resultados de performance dos leitões em recria na quarta semana experimental ( 22 a 28 dias).

\begin{tabular}{|c|c|c|c|c|c|c|}
\hline \multirow[b]{2}{*}{ Item $^{a}$} & \multirow{2}{*}{ Bloco } & \multicolumn{5}{|c|}{ Tratamentos } \\
\hline & & CONT & $200 \mathrm{SUL}$ & 50CIT & $100 \mathrm{CIT}$ & $150 \mathrm{CIT}$ \\
\hline \multirow{5}{*}{ GDP, g } & 1 & 614 & 803 & 657 & 657 & 578 \\
\hline & 2 & 592 & 707 & 675 & 514 & 572 \\
\hline & 3 & 664 & 550 & 560 & 610 & 596 \\
\hline & 4 & 664 & 553 & 675 & 478 & 557 \\
\hline & Média & 634 & 653 & 642 & 565 & 576 \\
\hline \multirow{5}{*}{ CDR, g } & 1 & 936 & 1272 & 1064 & 1022 & 1039 \\
\hline & 2 & 939 & 1125 & 996 & 991 & 1011 \\
\hline & 3 & 1172 & 972 & 964 & 1064 & 1096 \\
\hline & 4 & 1243 & 1189 & 1164 & 886 & 1014 \\
\hline & Média & 1073 & 1139 & 1047 & 991 & 1040 \\
\hline \multirow{5}{*}{ C A } & 1 & 1,53 & 1,61 & 1,62 & 1,55 & 1,79 \\
\hline & 2 & 1,58 & 1,59 & 1,47 & 1,86 & 1,77 \\
\hline & 3 & 1,76 & 1,76 & 1,72 & 1,74 & 1,84 \\
\hline & 4 & 1,87 & 2,15 & 1,73 & 1,85 & 1,82 \\
\hline & Média & 1,68 & 1,77 & 1,63 & 1,75 & 1,81 \\
\hline
\end{tabular}


Tabela A5. Resultados de performance dos leitões em recria nas duas semanas experimentais ( 01 a 14 dias).

\begin{tabular}{|c|c|c|c|c|c|c|}
\hline \multirow[b]{2}{*}{ Item ${ }^{a}$} & \multirow[b]{2}{*}{ Bloco } & \multicolumn{5}{|c|}{ Tratamentos } \\
\hline & & CONT & $200 \mathrm{SUL}$ & $50 \mathrm{CIT}$ & $100 \mathrm{CIT}$ & $150 \mathrm{CIT}$ \\
\hline \multirow{5}{*}{ GDP, $\mathrm{g}$} & 1 & 298 & 271 & 321 & 264 & 298 \\
\hline & 2 & 250 & 296 & 325 & 178 & 298 \\
\hline & 3 & 300 & 280 & 319 & 310 & 285 \\
\hline & 4 & 396 & 278 & 278 & 221 & 269 \\
\hline & Média & 311 & 281 & 311 & 243 & 287 \\
\hline \multirow{5}{*}{$\mathrm{CDR}, \mathrm{g}$} & 1 & 446 & 457 & 543 & 325 & 466 \\
\hline & 2 & 364 & 437 & 472 & 395 & 468 \\
\hline & 3 & 484 & 398 & 457 & 482 & 441 \\
\hline & 4 & 537 & 491 & 493 & 333 & 431 \\
\hline & Média & 458 & 446 & 491 & 384 & 452 \\
\hline \multirow{5}{*}{$\mathrm{CA}$} & 1 & 1,49 & 1,94 & 1,68 & 1,23 & 1,57 \\
\hline & 2 & 1,46 & 1,47 & 1,45 & 1,86 & 1,57 \\
\hline & 3 & 1,62 & 1,42 & 1,43 & 1,55 & 1,54 \\
\hline & 4 & 1,35 & 1,76 & 1,77 & 1,51 & 1,59 \\
\hline & Média & 1,48 & 1,65 & 1,58 & 1,54 & 1,57 \\
\hline
\end{tabular}


Tabela A6. Resultados de performance dos leitões em recria nas três semanas experimentais $(01$ a 21 dias $)$.

\begin{tabular}{|c|c|c|c|c|c|c|}
\hline \multirow[b]{2}{*}{ Item ${ }^{a}$} & \multirow[b]{2}{*}{ Bloco } & \multicolumn{3}{|c|}{ Tratamentos } & \multirow[b]{2}{*}{$100 \mathrm{CIT}$} & \multirow[b]{2}{*}{$150 \mathrm{CIT}$} \\
\hline & & CONT & $200 \mathrm{SUL}$ & $50 \mathrm{CIT}$ & & \\
\hline \multirow{5}{*}{ GDP, $g$} & 1 & 360 & 383 & 394 & 351 & 359 \\
\hline & 2 & 320 & 352 & 384 & 265 & 353 \\
\hline & 3 & 339 & 357 & 369 & 360 & 388 \\
\hline & 4 & 428 & 390 & 342 & 307 & 359 \\
\hline & Média & 362 & 371 & 372 & 321 & 365 \\
\hline \multirow{5}{*}{ CDR, g } & 1 & 553 & 597 & 672 & 478 & 604 \\
\hline & 2 & 489 & 576 & 604 & 519 & 579 \\
\hline & 3 & 606 & 542 & 582 & 607 & 614 \\
\hline & 4 & 656 & 649 & 600 & 457 & 568 \\
\hline & Média & 576 & 591 & 614 & 515 & 591 \\
\hline \multirow{5}{*}{$\mathrm{CA}$} & 1 & 1,53 & 1,76 & 1,71 & 1,36 & 1,68 \\
\hline & 2 & 1,53 & 1,63 & 1,57 & 1,73 & 1,64 \\
\hline & 3 & 1,78 & 1,52 & 1,57 & 1,68 & 1,58 \\
\hline & 4 & 1,53 & 1,66 & 1,75 & 1,48 & 1,58 \\
\hline & Média & 1,59 & 1,64 & 1,65 & 1,56 & 1,62 \\
\hline
\end{tabular}


Tabela A7. Resultados de performance dos leitões em recria nas quatro semanas experimentais (01-28 dias).

\begin{tabular}{|c|c|c|c|c|c|c|}
\hline \multirow[b]{2}{*}{ Item ${ }^{a}$} & \multirow[b]{2}{*}{ Bloco } & \multicolumn{5}{|c|}{ Tratamentos } \\
\hline & & CONT & $200 \mathrm{SUL}$ & 50CIT & $100 \mathrm{CIT}$ & $150 \mathrm{CIT}$ \\
\hline \multirow{5}{*}{ GDP, g } & 1 & 424 & 488 & 460 & 427 & 414 \\
\hline & 2 & 388 & 441 & 457 & 327 & 408 \\
\hline & 3 & 421 & 405 & 417 & 423 & 440 \\
\hline & 4 & 487 & 431 & 425 & 350 & 408 \\
\hline & Média & 430 & 441 & 439 & 382 & 417 \\
\hline \multirow{5}{*}{$\mathrm{CDR}, \mathrm{g}$} & 1 & 648 & 765 & 769 & 614 & 713 \\
\hline & 2 & 602 & 713 & 702 & 637 & 687 \\
\hline & 3 & 803 & 784 & 741 & 564 & 679 \\
\hline & 4 & 803 & 784 & 741 & 564 & 679 \\
\hline & Média & 700 & 728 & 722 & 634 & 704 \\
\hline \multirow{5}{*}{$\mathrm{CA}$} & 1 & 1,53 & 1,69 & 1,67 & 1,43 & 1,72 \\
\hline & 2 & 1,55 & 1,62 & 1,54 & 1,77 & 1,68 \\
\hline & 3 & 1,77 & 1,61 & 1,63 & 1,71 & 1,67 \\
\hline & 4 & 1,65 & 1,82 & 1,74 & 1,62 & 1,66 \\
\hline & Média & 1,62 & 1,68 & 1,64 & 1,63 & 1,68 \\
\hline
\end{tabular}


Tabela A8. Resultados de performance dos leitões em recria durante as duas últimas semanas experimentais ( 15 a 28 dias).

\begin{tabular}{|c|c|c|c|c|c|c|}
\hline \multirow[b]{2}{*}{ Item $^{a}$} & \multirow[b]{2}{*}{ Bloco } & \multicolumn{4}{|c|}{ Tratamentos } & \multirow[b]{2}{*}{$\overline{150 \mathrm{CIT}}$} \\
\hline & & CONT & $200 \mathrm{SUL}$ & $50 \mathrm{CIT}$ & $100 \mathrm{CIT}$ & \\
\hline \multirow{5}{*}{ GDP, $\mathrm{g}$} & 1 & 550 & 705 & 598 & 591 & 530 \\
\hline & 2 & 527 & 585 & 589 & 476 & 517 \\
\hline & 3 & 541 & 530 & 514 & 535 & 594 \\
\hline & 4 & 578 & 584 & 573 & 478 & 548 \\
\hline & Média & 549 & 601 & 568 & 520 & 547 \\
\hline \multirow{5}{*}{$\mathrm{CDR}, \mathrm{g}$} & 1 & 850 & 1074 & 996 & 904 & 959 \\
\hline & 2 & 839 & 989 & 932 & 878 & 907 \\
\hline & 3 & 1011 & 900 & 898 & 961 & 1028 \\
\hline & 4 & 1068 & 1077 & 989 & 795 & 928 \\
\hline & Média & 942 & 1010 & 954 & 884 & 956 \\
\hline \multirow{5}{*}{$\mathrm{CA}$} & 1 & 1,55 & 1,61 & 1,66 & 1,53 & 1,81 \\
\hline & 2 & 1,59 & 1,69 & 1,58 & 1,74 & 1,75 \\
\hline & 3 & 1,87 & 1,69 & 1,75 & 1,79 & 1,73 \\
\hline & 4 & 1,85 & 1,84 & 1,73 & 1,66 & 1,69 \\
\hline & Média & 1,72 & 1,71 & 1,68 & 1,68 & 1,75 \\
\hline
\end{tabular}


Tabela A9. Peso médio dos blocos dos tratamentos em cada período experimental

\begin{tabular}{ccccccc}
\hline & \multicolumn{6}{c}{ Período experimental, dias } \\
\cline { 2 - 7 } & Bloco & 0 & 7 & 14 & 21 & 28 \\
\hline \multirow{3}{*}{ Peso Médio, kg } & 2 & 7,515 & 8,960 & 11,585 & 15,280 & 19,915 \\
& 3 & 6,975 & 8,290 & 10,760 & 14,025 & 18,310 \\
& 4 & 6,250 & 7,755 & 10,295 & 13,930 & 18,030 \\
& Média & 6,848 & 8,261 & 10,871 & 14,377 & 18,676 \\
\hline
\end{tabular}

